Book Panel

\title{
Commuter lives: A review symposium on David Bissell's Transit Life
}

Alan Latham, Tim Edensor, Debbie Hopkins, Helen Fitt, Michele Lobo, Juliana Mansvelt, and Donald McNeill, with a response by David Bissell

\section{Contributors affiliation}

Alan Latham, University College London

Tim Edensor, Manchester Metropolitan University

Debbie Hopkins, University of Oxford

Helen Fitt, Lincoln University

Michele Lobo, Deakin University

Juliana Mansvelt, Massey University

Donald McNeill, University of Western Sydney

David Bissell, The University of Melbourne

\begin{abstract}
This article presents a series of commentaries on Transit Life: How Commuting is Transforming Our Cities (MIT Press, 2018). Centring on an in-depth case study of Sydney, the book argues for the need to attend carefully to the fine-grained detail of the commuting experience. In all sorts of ways, Transit Life presents a radically different way of thinking about urban transportation to that used by mainstream transport planners and geographers. Geographical Research asked six researchers-Tim Edensor, Michele Lobo, Debbie Hopkins, Helen Fitt, Juliana Mansvelt, and Donald McNeill—-to reflect on what kind of research vistas might be opened up bring the tools of cultural geography and mobility research to the world of commuting. Here are their responses, rounded out by a reply by David Bissell, Transit Life's author.
\end{abstract}

\section{Keywords}

This is the author manuscript accepted for publication and has undergone full peer review but has not been through the copyediting, typesetting, pagination and proofreading process, which may lead to differences between this version and the Version of Record. Please cite this article as doi: 10.1111/1745-5871.12382

This article is protected by copyright. All rights reserved. 
mobility; commuting; cities; infrastructure; temporalities; cultural geography

This article is protected by copyright. All rights reserved. 


\section{Introduction}

\section{Alan Latham}

I go into the over-crowded subway, mix with the people, I like all the shoving and pressing. I especially like the subway on rainy days: I enjoy the mixing up of anonymous coats moist with rain ... On the escalators I wink at one person, blow a kiss in the air. My kiss floats upwards or downwards and lands on someone like a soft little feather. (Ugresic, 1994, p.133)

Cities pulse to the rhythm of the working day. Weekday mornings and evenings tenssometimes hundreds — of thousands and, in the biggest metropolises, millions of people migrate from home to work or education and back. Some stop on the way to drop kids to school or day-care and to pick them up afterwards; and any number of other errands and social events are chained into that unrelenting rhythm. This movement represents a remarkable feat of technological, institutional, and social coordination. For many it doesn't feel much like that-stuck in a traffic jam, crammed into the sweaty crush of a commuter bus or subway carriage scoffing down breakfast cereal bars, or gifting several hours each day to the moloch of the daily commute, back and shoulders aching from sitting so long in one position waistline thickening. Yet a tremendous achievement the daily urban commute certainly is. It is one of the primal defining facts of life in affluent contemporary cities. Get up. Go to work. Go to school. Return home. Repeat. Even those not caught up in its maw-the retired, the freelancers, the unemployed, the stay at home parents, the slackers and the idlers and other refuseniks - must bow to its unrelenting presence. To be an urban dweller is to be in one way or another in transit.

Of course, the commute-transit—is not without poetry. Transit has gifted the English language a trove of affecting phrases. These describe not only the feeling of the commute, but also something of the existential qualities with which it is entangled. There are the obvious: “rush hour” ... “strap hanger” ... “gridlock’ ... “traffic jam”. To go with these are sayings such as "to miss the bus", "the end of the line", "to tell someone where to get off", and the wonderful "to be off one’s trolley"-from the American term for trams and more specifically 
the power arm that would regularly skip its guide bringing everything, vehicle and passengers, to an abrupt halt. We even have legal terms such as "the man on the Clapham omnibus" and its Australian equivalent "the man on the Bondi tram"-which describe the innate reasonableness of the average metropolitan citizen. These signal another thing about transit, its democratic dimension. It cuts across all strata of society. Everyone does it (or has done it). Not necessarily in the same degree of comfort. And not necessarily in the same modality. Yet transit spaces are often the most public spaces in cities. Not because they are where social differences are recognised. But because there is a certain universality to how they are experienced, and the emotions they engender. As Jack Katz (1999, p.80) writes of road rage between drivers on the Los Angeles freeway system:

\begin{abstract}
What is extraordinary in LA, is the motif in public life that "los ricos tambien se enojan” (the rich also get angry). It is, in a way, a triumph of Southern California's version of democracy that, substantially independent of their social status, people feel free to engage in behaviour that elsewhere would be eschewed as shamefully common and rude.
\end{abstract}

So, the world of the commute is not just infrastructure and machines, nor is it only economic rationalities and imperatives, and it is not simply about getting from A to B and back again. It is about more than that. This argument is a centre point of David Bissell's innovative study of Sydney commuters, Transit Life: How Commuting Is Transforming Our Cities (TL). Surveying the social science literature - to say nothing of that of engineering or the physical sciences - one would be hard pressed to find much trace of this poetry or passion. Of course, the infrastructures of transit are embedded in all kinds of formal knowledge; knowledge that is in no small part gathered, accredited, systematised, and taught by social scientists. Capacities to calculate and systematise sit at the heart of any modern city's ability to transport its inhabitants through its fabric. And there's a small universe of unglamorous professionstransport planners and modellers, route planners, civil engineers, electrical and mechanical engineers, payment specialists, and data and technology analysts—beavering away keeping cities’ transit systems functioning day-in, day-out. 
Still, when in his introduction Bissell suggests that the daily commute has been overlooked and undervalued by much of the social sciences, he has a point. But those who have been doing the overlooking are the funkier, more avant-garde, more cutting edge culturally infected theoretically obsessed, parts of the social sciences. More quantitatively oriented colleagues who have been plenty interested in transit, commuting, and infrastructure over the decades might well ask: What does thinking about passion, poetry and, by implication, embodiment, add to our practical understanding of commuting ${ }^{1}$

This question forms the challenge taken up in six chapters in Transit Life as Bissell works with the tools of cultural geography and mobility studies and enlivens, expands, and advances our understandings of how commuting gets done. What happens when a culturally oriented social scientist such as Bissell watches and listens to how commuting gets done? What perspectives open up? What gets noticed that might have otherwise been overlooked? And how useful and effective are the accounts and concepts produced by such an approach? To help answer these questions we asked six scholars to write commentaries on Transit Life. We start with a reflection on the importance of populating the transit journey.

\section{The rich texture of the journey}

\section{Tim Edensor}

Scholarly accounts of mobile practices have often conceived journeys as blank occasions, punctuated only by delays, discomforts, and unsociable behaviour. Accordingly, much attention has focused on the technical expertise required to develop efficient transit systems. Transit Life commendably extends thinking about everyday mobilities and counters simplistic assumptions that commuting is a banal, largely negative experience. David Bissell thoroughly dispels such misconceptions and preoccupations, providing a compendium of rich, evocative empirical material that testifies to an admirable capacity to empathetically engage with those involved in experiencing, reporting, and managing transit around Sydney. He shows how, as an integral part of the sensory and affective experience of everyday living, commuting can provoke surprise, inform discourse, and sustain intimacies. Judiciously chosen, provocative ideas are backed up by an array of conceptual tools that align with many contemporary geographical concerns, but a light touch always ensures that the non-academic reader will not 
be overwhelmed by rarefied theoretical discussion. In resisting the temptation to seek recourse in dense, joyless prose, this text is exemplary in its lively, grounded, and personable narrative.

The varied experiences of commuting, its affective intensities, sociabilities, and sensations are all richly rendered to highlight that the commuter is neither a passive nor blank figure. Indeed, commuting is revealed as part of an ongoing flow of experience, replete with shifting tones that flit between frustration, boredom, and anxiety as well as animated conversation, reverie, and productive forms of work and leisure. Emphatically refuting generalisations, we learn that each commuter's experience and outlook are shaped by different dispositions and attunements, and by distinctive journeys, individual routines, and family and work trajectories. Indeed, the commuter can never constitute a singular category, for even individual experience continuously shifts.

In responding to the wealth of stories and ideas that course through Transit Life, I offer five considerations. First, I believe that an exclusive focus on Sydney provides one of the book’s strengths. This approach identifies the distinctive commuting patterns, regular experiences, and articulations that occur in one place, while inviting the reader to draw parallels with commuting practices and experiences elsewhere, thereby undergirding the geographical specificities of the forms of transit with which our everyday lives are entangled.

Second, one particular story has salience for considering how we manage disruption, mishap, and disaster: following several unpleasant, scary incidents with motorists, experienced cyclist Brian suffers a loss of confidence; he must subsequently aim to restore his selfassurance so that he can once more confidently commute by bicycle-for him an important quotidian habit (TL, chapter 1). This case offers a profound insight into the everyday forms of management and maintenance we undertake to ensure that our routines and favoured practices are sustained. Brian's fortitude offers a minor yet profound insight into the intrinsic quality of the unnoticed endeavours through which everyday social and embodied practices are maintained, repaired, and amended.

Third, I want to focus more critically on Bissell's foregrounding of the becoming and immanence of commuting. This focus point certainly has the virtue of highlighting how each daily experience is different, charged with different intensities, dispositions, and moods, and shaped by what is happening around us. It also underpins the important argument that transit 
space, like all social space, is continuously emergent. Yet this emphasis comes at the cost of rhythm, as becoming overwhelms recurrence and reiteration. It is true that commuting is often hyperbolically conceived as emblematic of repetition, a signifier of the tedious mechanical reiteration that pervades contemporary urban life. Nevertheless, commuting is surely replete with regular rhythms, with systems governed by timetables and the regulation of traffic flow, not to mention the ceaseless practices of maintenance and repair that facilitate smooth transit. Furthermore, commuting involves acts of synchronisation that ensure that people can effectively meet, clock on, and manage social routines. Such rhythms are part of the temporal norms that organise social interaction: the 'when, how often, how long, in what order and at what speed' that are governed by a host of 'norms, habits and conventions' (Adam, 1995, p.66). This process does not infer that rhythm is endlessly repetitious. As Lefebvre (2004, p.6) emphasises, there is no 'rhythm without repetition in time and space, without reprises, without returns, in short, without measure', but also 'there is no identical absolute repetition indefinitely ... there is always something new and unforeseen that introduces itself into the repetitive'. Accordingly, transit rhythms are dynamic; some commuters create their own rhythms, while traffic jams and accidents generate arrhythmia. I want to ask: how might we more plausibly account for the tension between becoming and repetition in commuting and across social life more generally.

Fourth while rich descriptions of commuting provide compelling accounts of stations and vehicular interiors, the space travelled through is blank, except for the commuter who delights in the vision of Sydney Harbour en route to work. This absence contrasts with Paola Jiron Martinez's (2010) depiction of the daily commuters on Santiago's Metro system who enjoy recurrent scenic views of distant mountains and verdant landscapes. In Transit Life, the impression is that a sense of place is solicited solely in the interior of a car or train, yet a thickened, extended sense of place might emerge over time along the same stretch of road or railway (Edensor, 2003). During an oft-repeated journey, familiar landscapes, landmarks, and buildings are serially experienced, while a newly constructed house, freshly daubed piece of graffiti, or peculiar vehicle stand out from the usual scene, at certain points, tickets, food, and newspapers may be purchased. 
Finally, and revelatory for me, was the prominence accorded by Bissell to notions of voicing. Besides the travel reports, utterances of road rage and journalistic accounts, I was struck by the internal monologue that accompanies transit as well as other everyday experiences. Such reiterative phrases are difficult to access because they only arise in the moment. Sometimes, when there is no-one around, this repetition transmutes into actual outbursts of speech, but I am aware that my mundane engagement with the everyday is replete with multiple phrases, nonsense words, banal extracts of song, and guttural refrains that are wholly immanent and never the focus of reflection. They somehow mark the unfolding things that happen and articulate with moods and affects.

We remain with these voices in the following section as Michele Lobo takes us on a journey through Melbourne.

\section{Lively voices and visceral encounters}

\section{Michele Lobo}

I can hear the rants from Sydney commuters, see the electric purple jacaranda trees in full bloom, and smell the lemon-scented gums even though I am reading this book while I travel by train in wintry suburban Melbourne. David Bissell's book changes the conversation about the politics of commuting using thick multisensory descriptions of everyday travel that decentre the authoritative voices of transport planners and policy makers. These experimental interventions of grounded multivocality entangle openness to affective forces that swirl in everyday spaces. These visceral forces escape attention because sensory registers are difficult to capture or are perceived as less important in imaginaries of the transit city. For Justin, a participant who curates a mobile drive-time radio show, however, these registers are an essential ingredient of good storytelling (TL, chapter 5). His passion for drawing out stories from callers and keeping a collective community of listeners engaged is evident when he says, 'I'd like to be able to tell a story so that people go “Gees, hang on; that guy's never going to be the same again after today. That's an incredible thing that's happened to this person; it's really changed their life' (p.128). Listening to Justin, it seems that storytelling is a performative act of humbly 'creep[ing]' (p.128.) inside persons as well as places in ways that can change lives. 
Such acts of humility run through this book-David is the storyteller out there on the streets learning embodied skills from commuters. While doing a cycling course on the terrifying streets of Sydney, he is invited to be courageous in the midst of discomfort by the instructor who says, 'Fake it till you make it' (p.15). Here the practice of faking involves developing habits that are inventive and creative in exploring the micropolitics of transit life. We are encouraged to learn how to "bead" stories with an ethics that embodies humility but also courage and creativity.

Beading suggests a thick texture and vitality to transit life-activities bead everyday life, commutes are beaded with events and affective intensities bead interviews with participants. Rather than analysing and mapping large data sets such as journey to work data or critiquing policy/planning discourses, this book lets us feel the force of lively voices, everyday spaces and differentiated bodies. But Ruth (TL, chapter 6), a story activist and a member of the Sydney alliance — a non-party political organisation — is aware of how stories can be dismissed in main stream transport planning when she says, 'Collecting stories is one thing, but what are you going to do with them?' (p.156): Bissell shows that he knows what to do. Following feminist scholar, Donna Haraway (2016) his stories become like the air we breathe, invigorating us with a refreshing breeze. When we feel claustrophobic with familiar frameworks, promises, and goals related to planning policies and implementation plans, the stories in this book stimulate experimental thinking for the road ahead.

That road opens up through an immanent politics that beads theoretical insights on habit, affect, and the technological unconscious from geography, philosophy, anthropology, and sociology, as well as from interdisciplinary scholarship. Performative thinking, an ecological approach, and a light theoretical touch make reading the work an immersive as well as personal experience. We enter the space-time machine as we journey with Bissell and his grandfather (TL, Introduction) and accompany him on the bus to college in the United Kingdom. But it is second chapter, 'Fizzing Intensities', that focuses on loud conversations and tense encounters in Sydney that provides insights into eye-opening intersections of gender, generation, and class - teenaged boys, office workers, and women with strong accents unsettle quiet atmospheres. Travelling with Bissell on one of the busiest commuting corridors from Sydney to Wollongong, we hear boys sneer at "gold diggers” and threaten passengers with 
“toy guns”. But fizz also transports me to commuting spaces in Kolkata, India- the boom of bursting soda-water bottles and buses aflame on the streets when pedestrians are mowed down on congested streets. The day following a fatal accident there would be a hartal-a strike that paralysed transport during which people squatted on the streets, marched in "processions" shouting 'cholbe na' (Bengali for 'we won't accept this'). The city came to a standstill and there was a collective demand for change that valued visceral views from the street.

Rather than take a view from nowhere or a bird's eye view, this book plunges us into commuting spaces through familiar moments in cities. For example, the slow death as traffic crawls on freeways; the rage that erupts when you are unable to board buses that regularly pull away from the kerb even though you frantically wave at the bus driver; freezing train compartments with temperature settings for 'liquid nitrogen’ in mid-winter; loud conversations about 'fake eye lashes' (p.36); suburban bus interchanges that are 'islands of doom’ (p.41); and jokes about fellow travellers who have 'sawdust for brains’ (p.31).

I was immersed in these stories as I took the one-hour journey to the city from Hallam Railway Station in south eastern Melbourne on the busy Pakenham line. I was suddenly jolted by an announcement that reminded me that that the train trip would terminate at an intermediate station due to "planned works”. Perhaps it was sheer coincidence that I moved from reading the section of the book titled 'Rolling with it' to 'Stranded Expectations: Still waiting for Infrastructures'? I alighted at Westall Station and looked out for the express bus to Caulfield station—no sweet treats like hot doughnuts on this cold, rainy day. When casual transit staff shouted out Express Caulfield, I heard Espresso Coffee and said, 'Wow so glad, free coffee today!'. I was mistaken, we laughed, and convivial conversations on the bus made the longer three-hour commute to the city somehow bearable-did the optimism inherent in Transit Life vaporise and become contagious? Did we ride the wave of collective energy that sometimes emerges in shared mobile spaces? Surely such energy runs between the lines of this book and forces us to think differently about the politics of commuting.

Energies, of course, ebb and flow. They are part of the rhythms of commuting discussed already by Tim Edensor. In the next section Debbie Hopkins returns us these questions of temporality. Time—and ideas of spending and saving time-are central to mainstream 
transport planning. What happens when we extend thinking about travel time to focus more on thickness of how commuter temporalities are felt?

\section{Temporalities}

\section{Debbie Hopkins}

Time and temporalities are central to how we experience, practice, plan, and account for everyday mobilities. The multiple and divergent ways that time is known and felt can, perhaps most vividly, be articulated through stories of commuting - the various ways that people travel within, across and between cities between "home” and "work/study". Encounters with and active negotiation of time flow through many of the personal accounts captured in Transit Life, in which—without losing any of complexity—David Bissell neatly shows how the 'unexceptional activity’ of commuting ‘becomes exceptional' (p.xv). Questions about time have long been at the heart of transport scholarship, planning, and policy. The "value of time: has been debated and challenged, and a logic that prioritises the reduction of travel time has underpinned decision making, contributing to billions of dollars' worth of investment in "new and improved” physical infrastructures (for example, new/extended roads, high-speed rail). Travel time is calculated and compared; it is used to make sense of the city and has important effects. The different characteristics of natural and built environments mean that some places are easier to access than others, and that decisions are made (and have been made) that connect some places, while detaching others.

While time and temporalities feature strongly throughout the six chapters of Transit Life, chapter 3 on 'Squeezed Transition' is perhaps most attuned to and focused on the intersections of mobile life and time. There, Bissell sets out an alternative to traditional conceptualisations of time as something that can be objectively understood, counted, measured, filled, and emptied, and moves to a more processual and relational understanding of time that is 'actively created through our experiences' (p.54); in doing so, he points to the multiple and overlapping temporalities that inform and are informed by everyday mobilities. By offering a more diversified and situated conceptualisation of time, Bissell discards some of the typical tropes of time and travel, and the restrictions of understanding time in the form of hours, minutes, and seconds, and replaces this with detailed accounts of how time feels and is experienced. 
Routines of commuting are varied and exist in tight relation (synchronisation) with other parts of social life. This relationship means that commutes are often highly managed, yet choreographed into performances that, to the casual observer, may appear anything but organised. Routines may seem rigid or flexible but are likely to be both; flexibility in some respects is afforded by way of rigidity in another. Bissell presents accounts of accumulated embodied knowledge, of strategies used to simplify complex negotiations of timings, mode choice and family relations, of the affordance of "possibilities for action" and of transitional time - the spatio-temporal separations between home (life) and work (life) — that occurs as one transits. These insights are both powerful and valuable. They show how dependence on numerical data (for example, duration or cost of travel), used in isolation from their wider context, strips the socio-spatial and political dimensions of transit life. Such dependence has the potential to replicate the idea of travel time as wasted time, view travel behaviour as rational and cost-optimising, and miss the more complex picture of social life, and commuting as one component of this life.

There is something of a fascination with people who endure long commutes. And, as Bissell observes, what constitutes a "long commute” is changing, as 'our everyday lives are becoming more spread out' (p.62). While the concept of “super-commuting” is not new (Ngai, 1974), super-commutes in the twenty-first century are enabled by new technologies (for instance, air planes, high-speed rail), improvements to existing vehicles (automated features, comfort), and working practices (flexi-work), and consequently it is increasingly common to super-commute over growing distances. Bissell weaves together and narrates his participants' journeys in a way that neither romanticises nor catastrophises these extreme commutes, but rather lays bare the social lives of extreme commuters, as people with multiple, sometimes conflicting priorities, identities, responsibilities, and places. Through his writing we gain a deeper glimpse into these social lives, including their frictions and fluidities depicted in three 'portraits': tales of how super-commuters are affected by long journeys. From these highlydetailed, contextually-rich portraits, we learn about Diane’s household members, who 'live apart together’; about Kelly’s deferred ‘self-care’ for a future yet-to-come, and about Mike’s disconnect from his home community due to his extreme commuting. These stories make real the notion of what it is to super-commute and the overlapping temporalities. 
Bissell discusses the temporal strategies constructed and adopted by super-commuters to live with the pressures of long-distance commuting, but also shows how commuters reclaim time, occasionally in radical ways. Transit Life documents some of the actions that commuters take to reduce time spent commuting - or exit the commute all together. Eva, for instance, spoke about missed family and community life that spurred her to stop commuting and to set up her own business. Yet Bissell discusses how flexible working arrangements may not always lead to greater time with friends and family, but work to 'intensify working practice’, which could result in longer working hours replacing commuting time. Such insights point to the complex intersections of work-life, commuting, and social-life and how slippage between these distinct but interrelated dimensions, or reconfigurations, might have unexpected consequences.

Transit Life is remarkably accessible; the light-touch theory providing readers with the resources to seek further should they wish to do so, without becoming so heavy as to dissuade all but an academic readership. As the findings of this research, and the insights presented throughout Transit Life have practical and policy-facing implications, it is my hope that it will be read by those shaping our cities and their transport systems, contributing to a radical repositioning of the modus operandi, which accounts for how the lived experience of travel time is produced through variable, managed practice and generates opportunities and challenges. The insights gained from Transit Life can help us to rethink urban life in the twenty-first century in all its delightful complexity.

And we stick with the theme of complex temporalities of commuting in Helen Fitt's meditation on change, time, and social imaginaries within which 'transit lives' are entangled.

\section{Change, time, and imaginaries}

\section{Helen Fitt}

In Transit Life we encounter a conceptualisation of commuting that is both multiple ('made up of many diverse practices linked together in time and across different spaces’ [p.xxxiii]) and fluid (or ‘always in formation’ [p.135]). Drawing particularly from mobilities thinking and social practice theories, the book hums with an elegant undertone of resistance to the remnants 
of structural determinism that are sometimes described as haunting transport geography. As David Bissell notes:

Thinking about the events and happenings in our lives, both big and small, as just the playing out of fixed structures and already written scripts effectively reduces us to lifeless marionettes, with powers already decided upon in advance of action. [p.xxxiv]

The effect of this perspective is to open all elements of our transit lives to the possibility of change. From a perspective of recursive fluidity and multiplicity, though, I wonder: what does an appreciation of the possibility of change do? How does recognition of the possibility of change influence what change is possible? How does our perception of time shape our understandings of what is available to change and what is fixed? And how might we influence the perspectives of the 'unglamorous professionals' [Latham, this series] who have the potential to enact, stymie, encourage, or stifle change?

First, then, I find myself wondering how recognising the possibility of change might influence what change is possible. Our visions, imaginaries, plans, and strategies for future transport are strongly contingent on what we currently view as fixed or open to change. Bergman et al. (2017, p.171) report on 'the business as usual character of the vast majority of imagined futures'. This point may be especially important as new transport technologies, including driverless cars, electric micro-mobility, and even automated flying taxis, assemble on the horizon. Notably, recent perspectives on new commuting options demonstrate a tendency to restrict the scope of conceivable change. For example, some commentators assume a straightforward technological substitution of driverless cars into an otherwise largely unchanged transport system. More sophisticated views allow for wider changes, such as increased urban sprawl or reduced requirements for parking provision. Few commentators currently allow much scope for deeper social change such as shifts in the underlying patterning of social life or the constantly evolving relationships (between people, places, spaces, materials, and other actors) that are an intrinsic part of social practice perspectives, and of the way Transit Life conceptualises commuting. Our ability to envisage possible futures is critical to our ability to proactively (and perhaps selectively) prepare for them. If Transit Life is 
successful in changing how people think about commuting (p.xxxvi) then it could facilitate more appropriately complex visions of transport transformations.

Second, I wonder how our perceptions of time shape our understandings of what is available to change and what is fixed. Transit Life's reflections on time, while engaging and thought provoking, do not explore in detail the integral meshing of time with change. While Bissell resists structural determinism, he does allow for elements of stability, fixity, or mooring in the way he understands practices. He discusses 'longer duration social formations’ (p.xxii) and the way in which practices and systems can become 'deeply grooved' (p.xv). It is relevant, then, to ask if our understanding of the relationship between time and change influences the futures that we can conceive. It may be that infrastructures that seem fixed, tangible, concrete, and durable can change more quickly than social meanings that seem ephemeral, fleeting, intangible, and transitory. For example, we can trace shared meanings about the clientele of public transport services across more than 170 years (cf. Daumier, 1839; Meadows, 2012) but a viaduct that radically changes experiences of travel through the mountains can take just a couple of years to construct (Figure 1).

[take in Figure 1 here]

Exploring how time (whether seen as an objective reality, a social construction, or a bodily experience) shapes our understandings of what is fixed and what is open to change might help us to envisage transport futures effectively and proactively. Transit Life conceptualises transit as fluid but leaves the door open for the timescales of fluidity to be pursued in more depth elsewhere.

Third, I wonder how we might influence the perspectives held by the 'unglamorous professionals' [Latham, this series] who have the potential to enact, stymie, encourage, or stifle change. If we see ourselves not as lifeless marionettes in an endless rereading of already written scripts, it is surely appropriate to question what we will change and how. This book claims the ambitious project of changing how people think about commuting; however, it is not always clear who's thinking the book is targeted at or how it will be successful. Changing the thinking done by students, policy makers, politicians, journalists, and others comes with 
myriad challenges. Perhaps co-opting the concept of affordances [p.59] may enable us to consider how we can encourage the development of professional environments that are more amenable to a nuanced and complex perspective on the everyday.

Transit Life raises intriguing and important questions about how our transport systems and practices change. It can prompt us to question how we will allow commuting (amongst other experiences of mobility) to be transformed, what imaginaries we accept as valid (and what performative role they have in transit development), over what timescales our imaginaries extend, and how we might change the thinking of people enmeshed in different personal and professional environments. If the book's project is successful, it might just pave the way to more holistic and positive engagements with our transport future.

Both Debbie Hopkins and Helen Fitts' commentaries focus on the conceptual importance of Transit Life. The final two commentaries, by Juliana Mansvelt and Donald McNeill, offer more obviously personal responses to the book-Julianna reflecting on the everydayness of commuting, and Donald on questions of how and when new infrastructure "arrives" in cities.

\section{Making the everyday visible}

\section{Juliana Mansvelt}

Transit Life arrived in my office mailbox just before I was about to go on annual leave and my suitcase was at the airline's weight capacity. I was about to put the book in, when my husband suggested I take it out because 'it's a work book'. On reflection I wished I had taken it because with its 'tantalising encounters' it was just as engrossing as many a novel I have read, including an encounter David Bissell had with a participant who said, 'Well you don’t look like a knife wielding murderer, so let’s talk at my house!' My momentary and mundane conversation with my partner about my own travel plans seemed, on later reflection, to encapsulate so many of the themes examined in Transit Life; that is, the power of the voices that name, script, and classify transit journeys; the demarcation of what constitutes home, work, and travel spaces; the regulatory and infrastructural elements of mobility and the material things we move in and through; and the kinds of dispositions, senses, and emotions that influence and emerge from our journeys. Yet, this book is so much more than an engaging 
encounter with Bissell's extensive research on transit lives. The focus on intensities that captured my interest will likely resonate with many commuters themselves—but the affective dimension of the book, which takes the reader beyond statistical and descriptive accounts of journeys to and from work, potentially has wider effects in terms of intellectual and public reach of the monograph and its capacity to augment professional and institutional realms of knowledge.

In highlighting commuting as the 'sphere of everyday life fizzing with all manner of events and encounters' (p.xviii) Bissell does not simply add “colour: or "vibrancy” to existing accounts of travel journeys, statistics, or infrastructure. While it might not seem like "work" to read, Transit Life draws in and encourages its audience to reflect, to learn more, and to examine the theoretical and empirical provenance of Bissell's assertions and research. Part of his aim in writing the book has been to make visible an often-overlooked sphere of everyday life, but the monograph does much more by highlighting the wider significance of the mundane matters of journeys to and from work. For example, in reflecting on Claire's story of 'losing it' with a bus driver (chapter 2), recounting a moment of anger becomes an opportunity to examine how the planning, design, regulation, and practice of journeys to and from work can constrain and enable the expression of different dispositions. Drawing on ideas about mundane governance aired by Woolgar and Neyland's (2013), readers learn how dispositions intersect with ordinary objects and technologies to exacerbate existing social inequalities or to enact new social and spatial forms that challenge normative frames of being, behaving and becoming. Claire's recollection of a moment of rage demonstrates the complex assemblages of people, places and things that create commuting. Her story reveals how bad weather, congested buses, bus driver behaviour, tired commuters, moral norms, regulatory frameworks, and even time of day can coalesce to produce what Bissell describes as 'fizzing intensities'. Claire's story defies a singular reading, providing instead a foundation for various audiences to consider, reflect on, and even re-evaluate their understandings of commuting systems, journeys, and practices. Transportation companies, for example, may recognise in her words what it might mean to provide adequate bus shelters or enough buses as peak times, and what it might mean to rethink the role of the bus drivers in attenuating such affects. Bissell neither celebrates transit life, nor castigates it, but invites the reader-whether commuter or 
commentator, scholar or systems designer, planner, or transport provider — to consider the differing possibilities for how their transit lives might be.

While Bissell's work provides comprehensive and multi-layered perspectives on the ways in which transit life is produced, regulated, sensed, and made manifest, aspects of commuting life could not, I suspect, be given specific and full attention in the space of the book. Material things and environments from travel cards to infrastructures are present throughout the chapters but I imagine there is much more that might be said about the mobilities of things as part of the human and non-human assemblages of things that create transit life. The manoeuvring and accommodation of the boxes, buggies, bikes, car-seats, shopping bags, ICT devices that both enable and limit the possibilities of how people move and the kinds of practices that centre on these were not explored in depth (see, for example, Dant, 2008; Hansson, 2015). Much was said about the production of transit life, but I was also fascinated by the glimpses provided of consumption. Advertising that penetrates commuters' waiting and travelling experiences was touched upon but, again, there is perhaps more to discover about the ways in acquisition, appropriation, appreciation, divestment, and disposal of commodities might punctuate and configure journeys (see Evans, 2018). The forms of consumption that precede and enable journeys also shape the journey. For example, additional means to understand experiences, regulation and impacts of commuting are provided by considering both the spaces, socialities, and subjectivities produced by and in consuming moments and consuming practices over the course of journeys (listening to music, eating, drinking) and the consumptive nature of travel itself (wastes generated by and on journeys embracing everything from rubbish to pollution).

For three days each week, I travel to and from a rural to an urban area for work, but the other two comprise trips for school and voluntary and after-school activities for our children. Much of my research has been about older people’s lives after retirement, several whom also travel regularly to care for others, to shop, or to socialise. Transit Life, focusing as it does on journeys to and from work, is silent on whether we can or should accommodate these other “regular” journeys as part of how we move. Is there something to be gained by a more inclusive understanding of the subjects and practices of commuting? In successfully making 
visible the nuances of the everyday commute, this book will encourage a diverse readership to reflect on and challenge their own dispositions, practices, and understandings of transit life.

Of course, all the movement, the coming and going, the back and forth of 'transit life' depends on thick webs of infrastructural systems. All too often these infrastructures feel inadequate, or indeed never seem to arrive. This infrastructural deficit is the focus our final commentary.

\title{
Infrastructural Worlds
}

\section{Donald McNeill}

\begin{abstract}
One afternoon during my first fieldwork week at Castle Hill, I noticed a sign reading "Northwest Rail Link Information Center,” adorning an otherwise forgettable white building right next to the bus interchange. Cognizant of the troubled history of the project, I ventured inside. A promotional video played on a large flat-screen TV, flashing the keywords growth and future in time to a rousing, anthemic soundtrack. CGI renderings of new stations adorned the walls. (Transit Life, p.144)
\end{abstract}

One of the most memorable passages from Transit Life, for me, is a section that has no commuting going on at all. Yet, David Bissell has a poignant discussion with a representative of a transport department charged with promoting a new rail line extension to the public. She is optimistic, with an enthusiastic energy for this new project. Many geographers will be aware of this kind of urban artefact, and Bissell is right to linger on it. He taps into one of the more intriguing elements of the urban experience: the uncertain wait for a new public transport link to be provided. The 'disposition of still waiting', he calls it. Now I know finally what this is: I have heard it often living on Sydney's Northern Beaches where, for several decades, there has been talk of a fast tunnel that skips under all the inconvenient waterways and national park of this part of Sydney. Embedded within this talk is the sense that of the two main political parties, Labor will never build it because members and party leaders have a genetic hostility to the area; the Liberals will never build it because they need the money to spend in other areas with slightly less hostility and, which might deliver them into government. 
It is testimony to how fully Bissell has covered the commuting experience that he has identified one of the key elements of the state-public relationship, the sense of "project announced, project never turns up” that grips much of the population. I make this observation at a time of unprecedented investment in public transport in New South Wales, spearheadedsurprisingly for some- - by a Liberal-National state government, led by self-styled policy wonk, Gladys Berejiklian, who ascended to the Premiership direct from the transport portfolio.

One of the features of this uncertain optimism is the announcement of the feasibility study. The "feaso", as it is more commonly referred to in Australian policy circles, is a hefty piece of political technology. A study into high-speed rail under the Rudd Labor government (2007-10) came in at AU\$20 million. True, this was only a fraction of the projected cost of the \$114 billion network that would result. And it does, of course, seem to include the painstaking surveying, sensing, and modelling of the sizeable slices of land that would make up a future network.

These technologies of demonstration-scale models, information centres, and the new kid on the block, virtual reality headsets allowing a hands-on experience of a tunnel borer-are tantalisingly ephemeral. Should we be heritage listing these information centres, keeping everything, capturing the essence of optimism, of a low-level 'technological sublime', that a new piece of urban infrastructure brings to the city? In many ways, what Bissell is describing here is part of a wider interest in "anticipatory geographies”, in which future possibilities become part of the spatial practice of the present. Bissell touches on work in this area by Ben Anderson, and it is interesting to think a little more about what these anticipatory geographies might be. Anderson (2010, p.793) has made a series of programmatic statements about what the future might be and suggested that 'an analytics of how anticipatory action functions should attend to: styles, consisting of statements that disclose and relate to the form of the future; practices, consisting of acts that make specific futures present; and logics, consisting of interventions in the here and now on the basis of futures'. Varied activities, particularly in government — and ranging from calculating, imagining, and performing futures-use techniques from extrapolation to embodiment of 'as if' futures (p.787).

Two final thoughts: at a policy workshop recently, a member of the state transport agency made the point that each of the significant transport interventions and investments made by his 
agency were already at capacity, full up. He seemed to think that was a problem, though I thought it was a mark of success, and that he should stop moaning and be glad for small mercies. Anyway, he was worried, as were many of his colleagues, about the future, and the workshop had horizon scanning scenarios that ranged from climate change to jet-packs to blockchain to the anti-plastics movement. The barista next to the transport interchange was clear when Bissell quizzed him on the new rail link. 'He shook his head. "Nah, it's not happening," he says, bluntly. "We've been here before”' (p.144). He was right to be sceptical. But in this case, at least, it is happening ... and the commuters who will complain about it as it degrades into a public transport half-life in a couple of decades time are just being born ...

... which is tantalising place to leave our commentaries and hand over to David Bissell.

\section{Response}

\section{David Bissell}

At around the same time that Transit Life was published, I attended a workshop on the future of mobility in my new home city of Melbourne. The task for the fifty or so mainly industry attendees was to get into small groups and dream up an "innovation" that would improve the lives of commuters in the city ten years from now. Staggeringly, every one of the six groups came up with practically the same thing: a mobile app subscription service that intuited when and where you would need to travel based on your calendar, which would automatically summon a driverless vehicle and whisk you to where your calendar said you needed to be. Aside the most troubling elements of technological boosterism that were being embraced in this worryingly ubiquitous anticipation of future 'infrastructural worlds', to use McNeill's term, our location - hermetically sealed into one of the uppermost floors of one of the city's tallest skyscrapers - only seemed to emphasise the remoteness of these supposed innovations from the rough and tumble of people moving through the city streets below. Sensing this disjuncture reminded me of why I wrote Transit Life. There was next to no discussion of how different people might express different desires, no discussion of why we move around the city in the first place, no discussion about the impact that daily movements have on our lives. As Lobo's reflections on the book so thoughtfully illuminate, our daily journeys are a domain of 
everyday life chock-full of visceral encounters that quite simply make a difference. Yet it is precisely these experiential intensities of city life made up of transformative encounters, both big and small, that have largely been absent from more utilitarian accounts of commuting which can sometimes feel like they have been written from a distance.

This idea of transformation is the red thread that weaves through the entire book, as many of the contributors have acknowledged. The rationale for pursuing this theme is to complicate accounts of daily life that imply that is it a humdrum realm of unchanging repetition of the same, day in, day out, or that this is a part of life that is somehow resistant to transformation. As I argue in the opening chapter, these commutes are urban practices where previously, only certain kinds of transformation have been foregrounded, such as travel time between certain places, or the mode of transport that people take. These statistics can act as proxies for other sorts of changes that might be happening, but they don't tell us anything about the other more subtle transformations that are going on in this zone. In many respects, Edensor is right to acknowledge that it can often appear that some things are changing, while other things are staying the same. Indeed, as mobility scholars have long suggested, for things to be mobile, certain things need to be (relatively) still. But, and heeding Hopkins's reflections on taking time seriously, this is in part because different processes have different durations. Wheel marks are accruing in roads, bodies are ageing, infrastructures are being constructed, the sun is rising, a glance is reciprocated. Since conscious thought only registers a fraction of what is going on at any time, many transformations go unnoticed below the threshold of consciousness. Doing fieldwork for the book was an experiment in sensing and perceiving some of these diverse transformations of different durations, creating spaces and opportunities for sensing and perceiving differently.

Both Fitt and Mansvelt raise an important question concerning who or what is mean to be changed by Transit Life. I have adopted a style of writing that hopefully makes the book's arguments accessible to a broad range of people from inside and outside the academy. I would like to think that the book might be useful for people grappling with the question of how to make our cities better. For me, though, Transit Life is an archive of change taking place, rather than a prescription for a specific form of change. There are countless progressive transformations that we would hope to see in our infrastructural worlds. Thus, the contribution 
that this book makes to this question is to highlight that all transformations happen in the midst of complex ecologies of interacting forces, which trouble simple notions of effective agency and billiard-ball ideas about causality. As such, the forms of 'deep social change' that Fitt refers to, are difficult to evaluate, let alone induce, precisely because they are longer durational changes that can usually only ever recognised in retrospect. So, a new public transport infrastructure, such as the one explored in chapter 6, can potentially create transformations that are 'progressive' from the point of view of reducing carbon emissions and facilitating social inclusion, for example. But there are no guarantees about the myriad cascading changes that such an infrastructure might potentially induce in the domains of housing affordability, for a sense of place, or the transitional quality of day to day encounters that it ends up facilitating. Furthermore, as the interviews with policy stakeholders reminded me, the world of policy interventions can be as performative, intricate and emotionally charged as the dramas that unfold in train carriages and on buses.

My modest hope is that different people who read the book might be transformedhowever slightly, and in unpredictable ways-by some aspect of it. This transformation might involve reflection on how significant elements of one's own commute differ from those captured in the stories explored in the book. To this end, I am happy that contributors have identified elements that are not as prominent in the book as they expected, perhaps basing their views on their own commuting experiences. Mansvelt highlights the importance of thinking about the differential capacities of travelling bodies through the various things that they travel with, which enable and constrain travel. While the following story did not make it into the book, Liz, the teacher who features in chapter 3, told me that although she takes the train mostly, she drives if she needs to bring school marking home. I smiled at this, as it took me back to my own childhood, when my mum—also a school teacher-would pull up home in the car at the end of the day. A large yellow plastic box crammed with files and marking would be lifted from the boot and plonked in the kitchen for the evening; uneasily intensifying my sense now, writing this, of her own relentless “second shift”. In turn, Edensor was surprised that there wasn't more scenery en route. For me, this point perhaps emphasises how scenes beyond the vehicle are sensed more keenly at particular times by particular people. Take Tom, for instance, the journalist in chapter 1 who recounted the vividness of rainforest gullies perceived 
during his new commute following the greyness of his previous London commute. Or consider Alice in chapter 4 who spoke about the beauty of her train journey which contrasted sharply with the grey cell of a room that she works in. Or Mia, in chapter 4 whose partial sightedness increased the importance of catching specific visual cues from the window that signalled her location.

I often cast my mind back to people that feature in this book. When Transit Life was published, I emailed people who had indicated that they would like to be kept in the loop about where their interview ended up. The following day, my inbox was full of messages bounced from email addresses that no longer existed. For a project that took the best part of six years to complete, many of the interviews had taken place years before. In that moment, I felt a pang of real sadness. Those people and their stories, which had been my preoccupation for so long now, no longer had a reality in the way that I remembered them. Yet, in so many ways, those bounced emails affirmed the red thread of the book. People are doing things differently, in different places, likely doing different commutes. Life has moved on. In this small void, I find myself wondering whether Jenny the wannabe retiree in chapter 1 has managed to finish commuting yet. The teenage boys in chapter 2 who were supremely aggravating their fellow train passengers will be adults now, and I wonder where their paths have taken them. Infrastructural life has moved on too, as McNeill describes. Sydney now ripples out even further as grassy paddocks are bulldozed to make way for suburban dreams.

Panning back to the workshop high above Melbourne, this is a time when so much is being said about how the future of urban mobility should be transformed. As the workshop brought into sharp focus for me, so much faith is currently being placed in future technological solutions to unclear problems. What I hope the book expresses most forcefully is that transit life is a zone where things are happening now that make a difference. Next steps are being taken, every day, all around us. People are experimenting with different things; changing what they do on the move; reflecting on what they want; who they want to be. I'm grateful to the contributors of this review forum for their care and consideration in drawing out the differences that have moved them in some way.

\section{Editorial conclusion}




\section{Alan Latham}

Transit Life is a super book. It is a super book for all the reasons that each of the commentators have already explained-its attention to the rhythms of the commute; its commitment to accounting for the complexity and experiential depth of commuter life; its ability to translate intricate conceptual arguments into an accessible and convincing narrative; its willingness to experiment. But it is worth emphasizing that Transit Life is an important book for another, more disciplinary specific, reason. This review essay kicked off with the question, 'What happens when a culturally oriented social scientist such as David Bissell watches and listens to how commuting gets done?' The answer is that reaching the end of Transit Life the attentive reader has seen how the tools of cultural geography—and empirically rigorous qualitative research—open up research vistas that other, more conventional, more obviously policy oriented, approaches have overlooked or discounted. Transit Life isn't interested in concepts like 'embodiment' or 'affect' or 'temporality' and so forth because they are conceptually challenging (although they certainly are!). Its interested in these terms because without them social scientists are missing something vital, something centrally important, about how commuting gets done (and indeed about how cities hold together). Transit Life is an innovative book about cities and commuting. It is also a cutting-edge exemplar of the power of an engaged cultural geography.

1. David Metz asks just this question in his excellent The Limits to Travel. While open to the ideas aired by mobility scholars and others, he is perplexed by the theoretical obfuscations of parts of the his literature.

\section{References}

Adam, B., 1995. Timewatch: the Social Analysis of Time. Cambridge: Polity

Allen, I., 1995. The City in Slang: New York Life and Popular Speech. Oxford: Oxford University Press

Anderson, B., 2010. Preemption, precaution, preparedness: anticipatory action and future geographies. Progress in Human Geography, 34(6), 777-98 
Bergman, N., Schwanen, T., and Sovacool, B., 2017. Imagined people, behaviour and future mobility: Insights from visions of electric vehicles and car clubs in the United Kingdom. Transport Policy, 59(Oct), 165-73 doi: 10.1016/j.tranpol.2017.07.016

Dant, T., 2008. The 'pragmatics' of material interaction. Journal of Consumer Culture, 8(1),11-33.

Daumier, H., 1839. Riding on a bus between a butcher and a drunk [Caricature]. In: W. Sachs, 1992. For Love of the Automobile: Looking Back into the History of Our Desires, D. Reneau, Trans. Berkeley: University of California Press

Edensor, T., 2003. M6: Junction 19-16: defamiliarising the mundane roadscape. Space and Culture, 6(2), 151-68

Evans, D., 2018. What is consumption, where has it been going, and does it still matter? The Sociological Review, 0038026118764028. doi:10.1177/0038026118764028

Hansson, N., 2015. "Mobility-things” and consumption: conceptualizing differently mobile families on the move with recent purchases in urban space. Consumption Markets \& Culture, 18(1), 72-91.

Haraway, D., 2016. Storytelling for Earthly Survival. A film by Fabrizio Terranova.

Jirón Martínez, P., 2010. Repetition and difference: rhythms and mobile place-making in Santiago de Chile, in T. Edensor (ed.) Geographies of Rhythm. Aldershot: Ashgate, pp.129-43

Katz, J., 1999, How Emotions Work. Chicago: University of Chicago

Lefebvre, H., 2004, Rhythmanalysis: Space, Time and Everyday Life. London: Continuum

Meadows, R., 2012. October 11: Is riding the Loser Cruiser worth it? The Press. Retrieved from http://www.stuff.co.nz

Metz, D., 2012. The Limits to Travel: How Far Will You Go? London and New York: Routledge

Ngai, S., 1974. Long-distance commuting as a solution to geographical limitation to career choices of two-career families. Master's Thesis, Massachusetts Institute of 
Technology, June 1974. Available at:

https://dspace.mit.edu/bitstream/handle/1721.1/45187/23938219-

MIT.pdf?sequence $=2$

Ugresic, D., 1994. Have a Nice Day. London: Jonathan Cape

Woolgar, S., and Neyland, D., 2014. Mundane Governance: Ontology and Accountability. Oxford: Oxford University Press.

This article is protected by copyright. All rights reserved. 


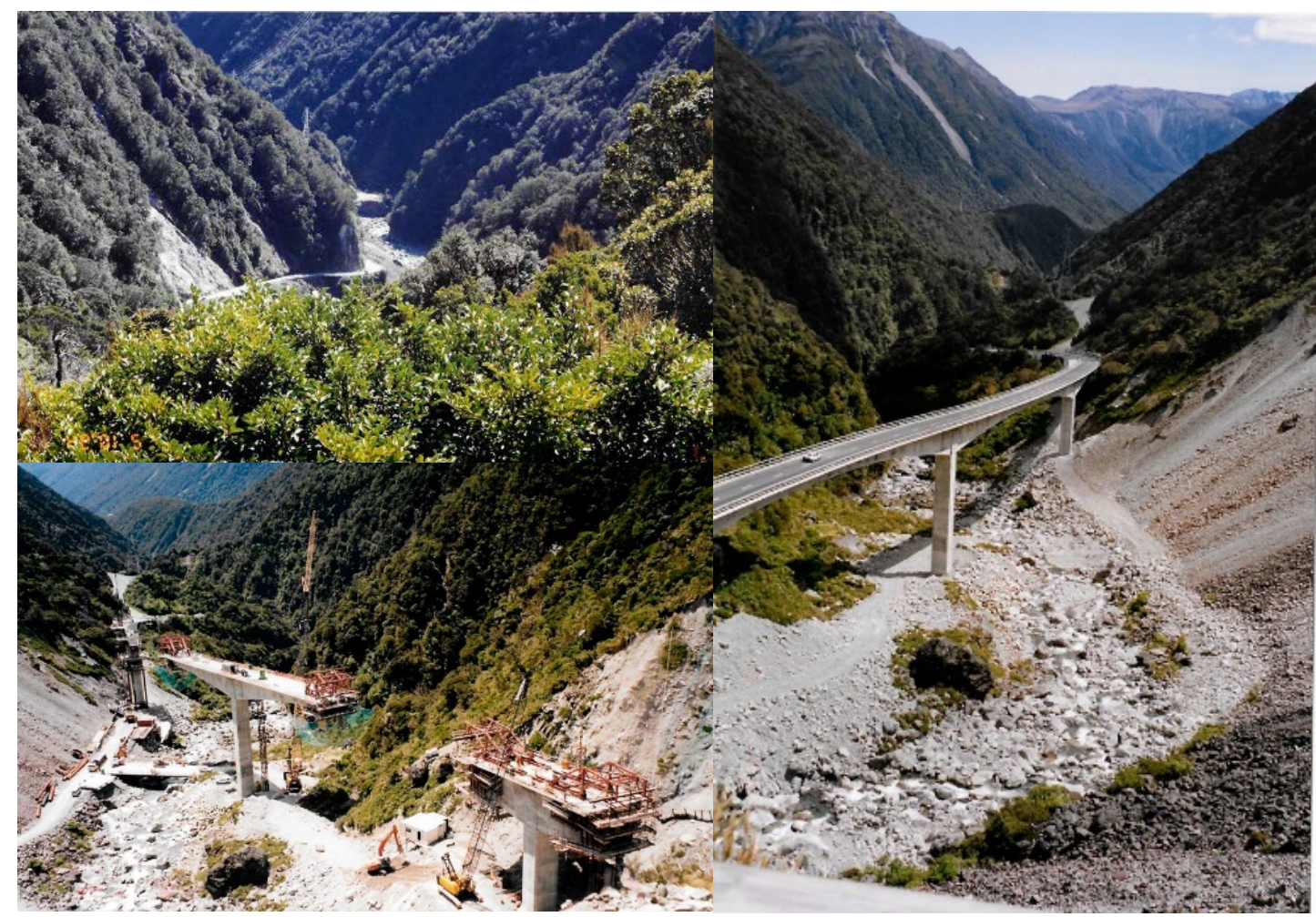

Figure 1: Construction of the Otira Viaduct, NZ: Before (a), during (b), and after (c). Source: West Coast New Zealand History (8th Oct 2016). Photo's [sic] of the old road Otira Gorge and the building of the viaduct. Photographer: Don Hutton. In Website West Coast New Zealand History. Retrieved 9th Oct 2019 15:29, from https://westcoast.recollect.co.nz/nodes/view/12762 


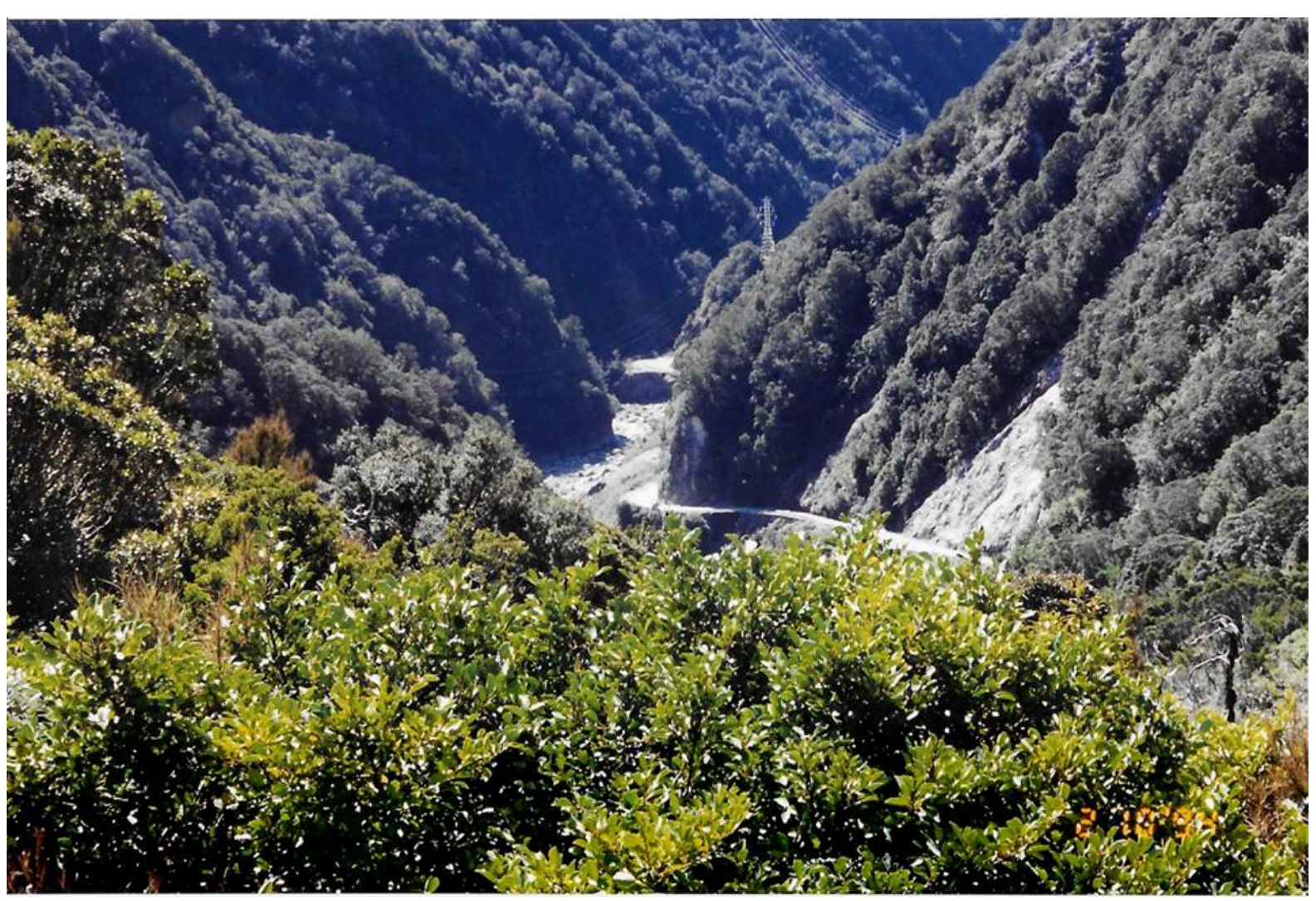

This article is protected by copyright. All rights reserved. 


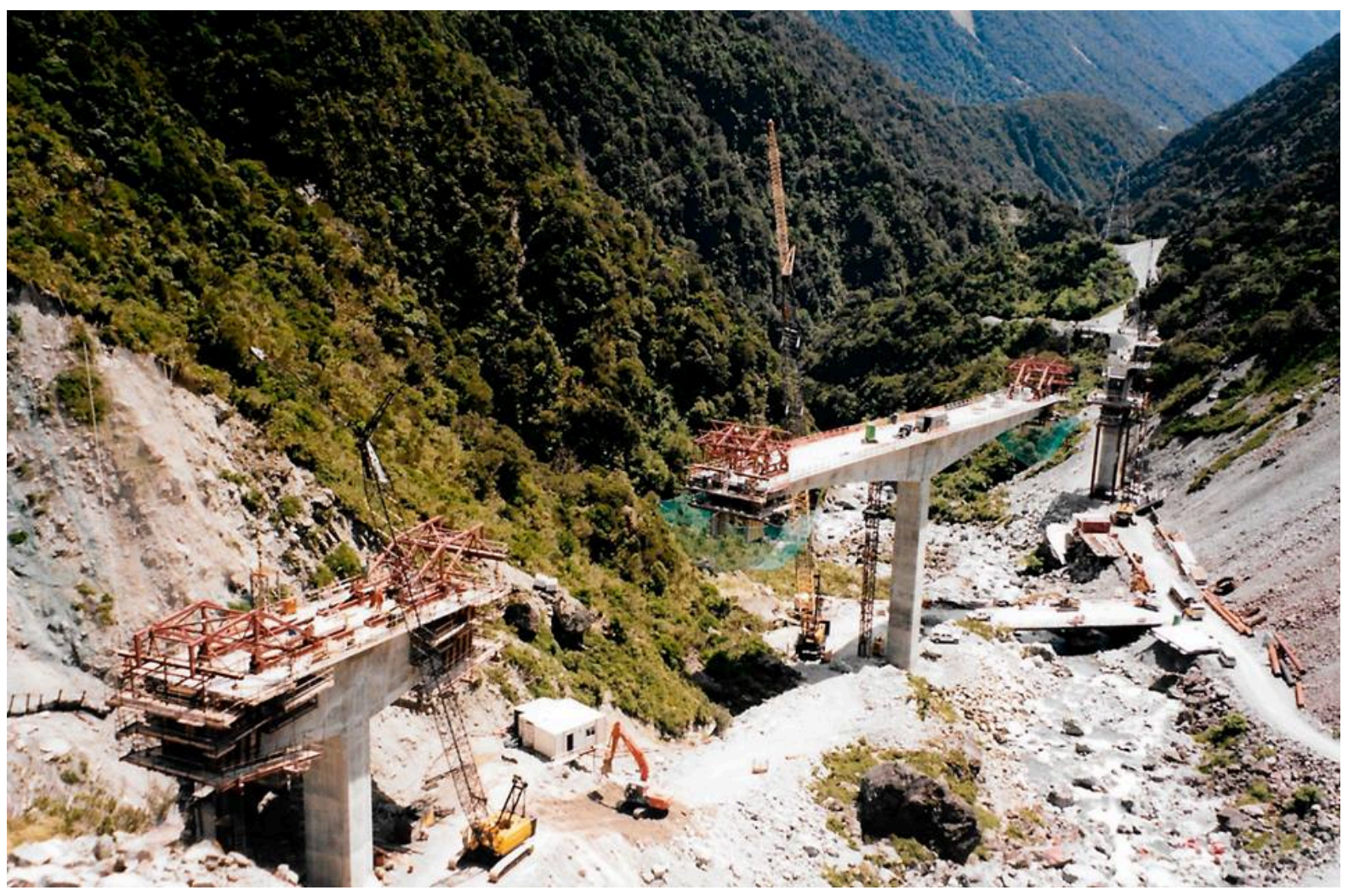

This article is protected by copyright. All rights reserved. 

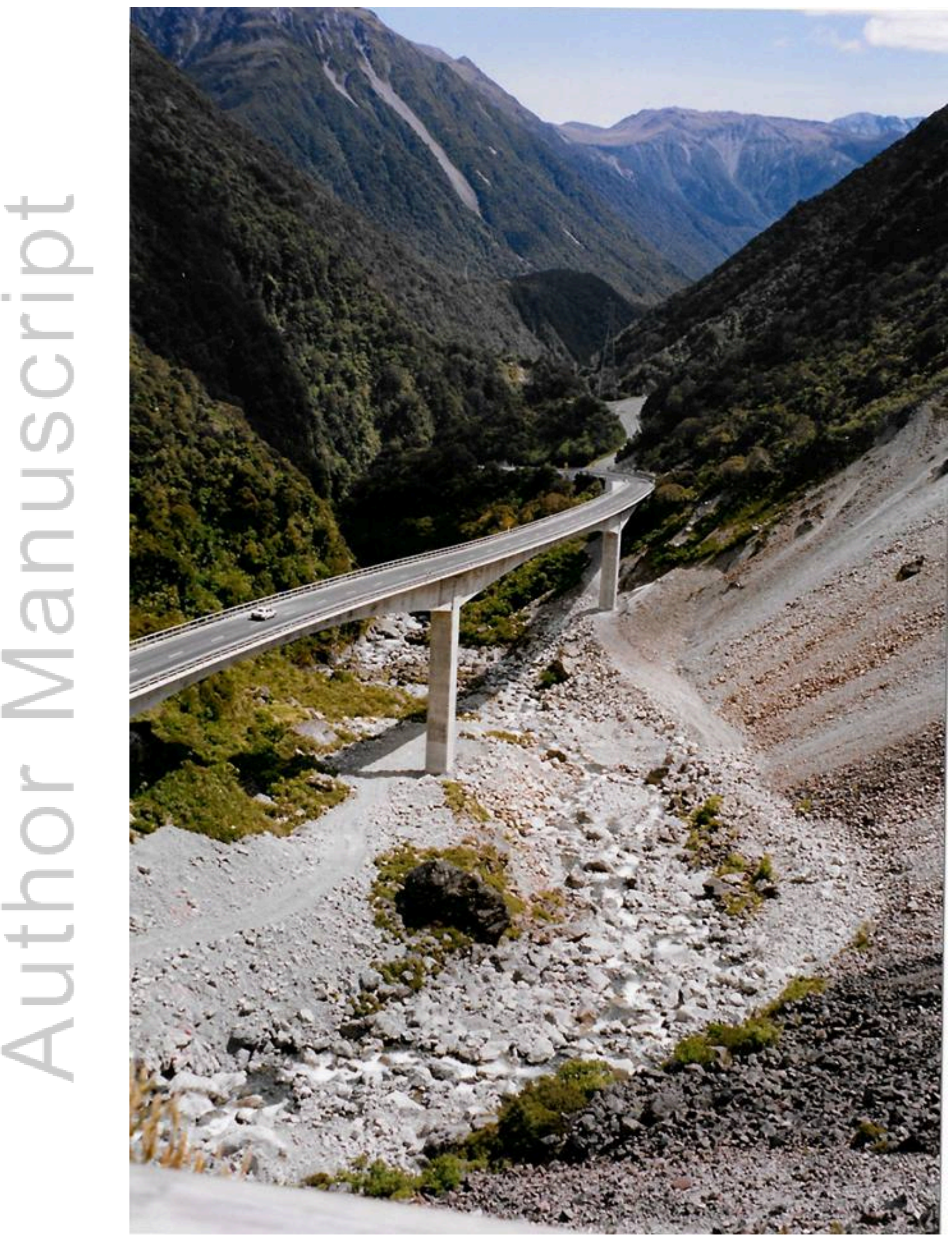

This article is protected by copyright. All rights reserved. 


\section{University Library}

\section{- M M N E R VA A gateway to Melbourne's research publications}

Minerva Access is the Institutional Repository of The University of Melbourne

Author/s:

Latham, A;Edensor, T;Hopkins, D;Fitt, H;Lobo, M;Mansvelt, J;McNeill, D;Bissell, D

Title:

Commuter lives: a review symposium on David Bissell's Transit Life

Date:

2020-02-01

Citation:

Latham, A., Edensor, T., Hopkins, D., Fitt, H., Lobo, M., Mansvelt, J., McNeill, D. \& Bissell, D. (2020). Commuter lives: a review symposium on David Bissell's Transit Life. GEOGRAPHICAL RESEARCH, 58 (1), https://doi.org/10.1111/1745-5871.12382.

Persistent Link:

http://hdl.handle.net/11343/286940 